This is an Accepted Manuscript of an article published by Taylor \& Francis in JOURNAL OF EDUCATION, PEDAGOGY AND CULTURAL STUDIES MAY 2010, Vol. 32, Iss. 2, 2010 available online: http://www.tandfonline.com/ Article DOI: 10.1080/10714411003799165 THIS ARTICLE WAS IDENTIFIED AS ONE OF MOST READ ARTICLES (AS OF JUNE 2016) : http://www.tandfonline.com/action/showMostReadArticles?journalCode $=$ gred 20

\title{
The Significance of Critical Theory for Restorative Justice in Education Short Title: Critical Theory and Restorative Justice Dorothy Vaandering.
}

Restorative Justice (rj), a distinctive philosophical approach that seeks to replace punitive, managerial structures of schooling with those that emphasize the building and repairing of relationships (Hopkins 2004) has been embraced in the past two decades by a variety of school systems worldwide in an effort to build safe school communities. Early studies indicate rj holds significant promise, however, proponents in the field identify that theoretical and evidence-based research is falling behind practice. They call for further research to deepen the current understanding of rj that will support its sustainability and transformative potential and allow it to move from the margins to the mainstream of schooling (Braithwaite 2006; Morrison \& Ahmed 2006; Sherman \& Strang 2007).

In this paper I argue that critical theory, a framework that has to my knowledge been employed minimally in the field of rj and education, exposes and then provides a means for addressing an important debate that has arisen, namely that of rj being conceptualized solely in terms of student conduct as opposed to the development of relationship and community. By using critical theory it is my intention to map out the limits in the field thereby enhancing the current philosophical understanding of rj practice in schools. I argue that further insights into

\footnotetext{
With thanks to Wayne Martino for his insights and feedback throughout the writing of this paper
} 
the implementation and sustainability of $r j$ in education can be developed by drawing on conceptual analytic frameworks about power relations as put forth by Freire (1970), and hooks (2003). In so doing, I highlight that while rj addresses issues of conflict and behaviour it cannot be understood solely in these terms if it is going to play a role in transforming the culture of schooling.

\section{The origins of different restorative justice perspectives}

Proponents of rj in the Western world consistently trace its roots to ancient indigenous and spiritual traditions that emphasized the interconnectedness of humanity with each other and their environment (Breton \& Lehman 2001; Hadley 2001; Zehr 2005). As such justice was understood more in terms of relationship than in judging right from wrong.

From an indigenous perspective, Wonshe (2004) identifies that rj is not a label or program used in First Nations cultures, but rather a "thread woven into the fabric of their lives" (257). Pranis, Stuart, and Wedge (2003) elaborate on this by identifying how the common use of peacemaking circles in all indigenous cultures illustrates the integration of an aboriginal worldview into an understanding of justice. Such a worldview

sees the universe as characterized by wholeness, unity, and connectedness. ...we treat each other in respectful and ultimately sacred ways, because we see each person as part of the whole and indispensable to it. We also see ourselves as connected to all other beings, and so what happens to them affects us too. Our connectedness gives us the responsibility to care for each other and to help mend the webs that hold us (68).

From this perspective, justice encourages the growth of community that acknowledges how all are in need of help and that helping others helps all involved at the same time. Everyone is both a giver and a receiver (Pranis 2005, 6).

From a spiritual perspective, Zehr (2005), a rj practitioner and scholar within the field of criminal justice, is situated within the Mennonite tradition. In the particular understanding of 
Scripture he describes, questions of crime and harm done to others cannot be separated from questions of poverty and power (153). As such justice is based on the relational concept of shalom - God's intention for how things are to be among people, between God and people, and even with nature (Yoder in Zehr 132). When justice is understood as concerning itself with need, not merit, when it is understood as an act of liberation, as an act of love which seeks to make right relationships, its concern is not with measuring if all individuals have equal basic liberties and rights, but rather with how to make things better for the poor and oppressed (136-157). People and their relationships are central. Wolterstorff (2006) encapsulates this when he identifies that for justice to be administered, primary justice must be acknowledged and this is present in social relationships when no one is wronged, when the worth of the other is placed in the forefront of our attention (31-32).

In contrast to these perceptions of justice as relationship-based, the current western rulebased perception of justice as fairness has arisen out of the Enlightenment where rational, objective thought was touted and sought after for determining how best to address injustice. More recently in this same vein, Rawls (2001) highlighted the connection between justice and fairness with two main principles--distributive justice (people have equal basic liberties) and the difference principle (inequality only if open to all and it is to the benefit of the least advantaged people in society). Arising from these is the principle of 'justice as deserts' or retributive justice which gives authority and responsibility to those appointed to positions that oversee adequate distribution of resources and implementation of difference. In this way justice is seen to be served "by the impartial functioning of institutional procedures" (Breton \& Lehman 2001, xiii).

This western understanding of justice has been taken up and administered by an institutionalized judicial system that has come to emphasize rights over responsibility resulting 
in escalating crime, prisons filled to capacity, and high rates of recidivism. To re-introduce this judicial system formally to a more restorative approach Mark Yantzi, a parole officer in Kitchener, Ontario in 1974 sought court permission to bring two youth involved in vandalism to face the farmers whose property they had damaged. This replaced a court hearing and was successful in terms of repairing harm and introducing all involved to the fact that they were in relationship with each other. Since then, the judicial systems in most western countries have been engaging with the approach in various ways and with varied success.

Educators involved in schools for youth involved in crime and removed from the regular system began to engage with the rj approach as employed by the judicial system (Wachtel 1997). Armed with stories of success, and recognizing that the success came about because high expectations and support were provided for students so that relationships were established and restored, it was introduced to regular schools. Because schools were searching to prevent incidents of violence such as those experienced in Columbine, Colorado and Taber, Alberta, they began to engage with a wide variety of policies and procedures in hopes of ensuring their constituents that theirs was a safe school environment. $\mathrm{Rj}$ is one of many approaches to which schools turned.

Because the current engagement schools have with rj comes out of a judicial context and because schools are actively searching for ways to address issues of bullying, violence, and safety, $\mathrm{rj}$ is most often understood in the context of managing student behaviour. The foundational concepts of the interconnectedness of life and honouring the worth of all are minimized as education institutions seek to fulfill their social responsibility for enacting western understandings of distributive and retributive justice. 
From this angle, behaviour and learning are approached separately. Though educators realize that environments where youth are engaged in inappropriate, destructive behaviour are not conducive for learning, there is little recognition that the learning environment itself may be contributing to the responses of the students. Though Dewey is not a critical theorist, his experiential approach signals the depth of influence educators' responses to behaviour can have on learning and points to a need to reflect critically on institutional structures as well. In the following excerpt from "How We Think," Dewey (1916) highlights the long-term impact of engaging with rule-based justice in schools.

Conformity of acts to precepts and rules is the easiest, most mechanical, standard to employ. It is not part of our present task to tell just how far dogmatic instruction, or strict adherence to custom, convention, and the commands of a social superior, should extend in moral training; but since problems of conduct are the deepest and most common of all the problems of life, the ways in which they are met have an influence that radiates into every other mental attitude, even those far remote from any direct or conscious moral consideration (54).

Though Dewey highlights behaviour in this excerpt, what is important to note is the connection he draws between rote adherence to rules, pedagogy, and mental development. He links behaviour, learning and pedagogy in a way that the field of rj in education has not provided strongly enough. It is my premise that critical theory further strengthens this connection in its recognition that behaviour is situated within a institutional and community context that is often overlooked or ignored as a result of broader hegemonic influences. As the gaps and flaws in the current understanding of rj and its practice in schools are made visible, pedagogical implications arise that have significance for changing rule-based, managerial structures of schooling to relationship-based, community structures can be strengthened.

\section{Why critical theory?}


Kincheloe and McLaren (2000) in defining the role of a social theory in a research context indicate that a theory is not a lens through which we see the world but rather a tool to help us 'devise questions and strategies for exploring it" (281). In this light critical theory allows for an interrogation and examination of rj so that those involved in the fieldpractitioners and researchers--are more explicitly aware of how rj has come to be, whose interests are served by the implementation of rj, and where our frames of reference come from (303). In employing critical theory in this manner as a tool, the organizational and relational structure of the school is scrutinized "in order to prevent the further resecuring of the ideological hegemony" (304) of the rule-based, managerial structures of schooling. This is significant as the premise of rj seeks to transform society's current understanding of justice and requires, as Zehr (2005) indicates, nothing less than a paradigm shift (94). Without a critical examination of education and the current practice of rj in education, rj risks being coopted as Canadian social justice activist Ruth Morris indicates when she says:

By accepting the myth that problems in the world begin with the offender, by ignoring structural injustice, by attempting to restore the past, rj is vulnerable for co-optation. Although rj seeks to be different, and usually is, some jurisdictions in the United States and Canada have borrowed the language of Restorative Justice for programs that are highly punitive and destructive (Morris as summarized in Moore 2003, 34-35).

Finally, critical theory is about more than producing further knowledge. Its commitment to action that will address injustices uncovered in the field being studied is necessary for rj which too has set out to address injustices.

Aoki (1989) in reflecting on how people engage with the world, identifies a continuum of orientations ranging from technical to interpretive to critical. These orientations are helpful in 
considering the manner in which schools engage with rj and highlight further why critical theory is important for extending and deepening a rj knowledge base. A technical orientation emphasizes people's engagement with the world for the purpose of producing empirical knowledge that allows them to be in control and live with certainty (10). Much early and current engagement with literature available regarding rj in education can be located within this orientation. The success of rj in schools is reported in terms of the reduction of suspensions, expulsions and students sent to the office for behavioural issues (IIRP, 2009; Mirsky \& Wachtel 2008; Porter 2007; Drewery \& Winslade 2006; Youth Justice Board 2004). In assessing the success of $\mathrm{rj}$ in this manner, questions arise in terms of the purpose of employing rj-is it really about establishing relationship-based environments or is it being employed to better manage and control students?

An interpretive orientation emphasizes people's engagement with the world for the purpose of producing meaning tied to relationships and situations. Certainty is less important than curiosity or the mystery life holds (Aoki 1989, 10). More recently emphasis on and literature available regarding $\mathrm{rj}$ in education can be found within this orientation as it is no longer focused on just restoring broken relationships and repairing harm but is more explicit in regards to the need for building and affirming relationships as foundational for responding to inappropriate student behaviour (Morrison 2007; Thorsborne \& Vinegard 2002; Hopkins 2004). Though broader in perspective, like the technical orientation, the interpretive orientation continues to focus on individuals affected - youth in particular-- with little attention given to their social context. As a result, adultist tendencies where student behaviour is seen as serving adult purposes, continue to be encouraged. 
A critical orientation emphasizes people's reflective engagement with the world for the purpose of "rendering transparent tacit, hidden assumptions" that will then lead to action that improves the overall human condition. Life and reality are found in praxis (Aoki 1989, 10-11). For Aoki this critical understanding is informed by theorists from the Frankfurt school and Freire who draw attention to the importance of understanding the individual within the context of broader social structures and systems. To date such a critical orientation has rarely been used to inform approaches of implementing rj in school communities. It is my premise that in order for $\mathrm{rj}$ to be effective and sustainable it must be understood first and foremost through a critical lens that recognizes the systemic, institutional and structural dimensions of power relations in school communities. Focusing on individuals without considering contextual factors results in objectification that reinforces the wishes of hierarchical power relations stripping both the individuals and the institutional community of their humanity (Freire 1970, 44). Through critical theory then it is possible to understand rj in a broader sense, where all participants in a school—adults and youth—are respected for their humanity and effective communities develop where the well-being of all is sought.

Prior to expanding on the contributions Freire and hooks make to the field of rj in education, I provide a very brief historical overview of rj in Ontario and a summary of rj principles.

\section{Restorative justice in educational institutions}

Restorative practices in education have evolved from the principles of $\mathrm{rj}$, which have been used formally in North America since the 1970's to address the limitations and needs in the judicial system that came about as a result of its punitive, retributive stance. The understanding of justice that emerged at that time sought to involve offenders in understanding the 
consequences of their actions in hopes of being better able to bring restoration and healing to all who had a stake in the situation. For society to understand justice as such, Howard Zehr's (2005) pioneering work in the current rj movement, identified that nothing less than a paradigm shift was required (94). Coming from the judicial system however, in spite of Zehr's focus on justice as shalom, the focus of rj continued to be on behaviour and wrong doing, not on relationship. As a result initial and most current perspectives of rj are first understood by contrasting adversarial and restorative views of wrong doing as summarized in Table 1 which has been adapted to present the perspectives encouraged by the Ontario Safe Schools Act 2000 (an adversarial paradigm) and those encouraged by a rj paradigm.

[Insert Table 1]

Not only does this chart illustrate two different approaches to addressing wrong doing, it also reveals different approaches to education that can be defined in broad terms using Freire's (1970) insights. The OSSA 2000 reflects a banking model of education where students are objectified and managed in an effort to fit into boxes that benefit adult expectations. The results that eliminated large numbers of non-compliant youth from school environments for some could be seen as success as opportunities and effectiveness of transmitting knowledge to willing receptacles grows; for others who engage with education in a manner emphasizing Freire's (1970) dialogic, interactive approach as a means for creating a better learning environment and ultimately a better world for all, recognize the impact disenfranchised youth have on the broader society and the harm that results for everyone.

Zehr (2005) and Braithwaite (1999) indicate that rj acknowledges that all people and their needs are considered worthy. When harm is done, justice that emerges from a rj framework seeks 
to bring restoration and healing to all who have a stake in the situation. In a school setting, Wachtel (1999) and Amstutz and Mullet (2005) describe a range of restorative practices that promote supportive, yet limit-setting environments that aim to prevent and repair harm done to individuals, relationships, and their communities. This restorative, relational approach is unique in comparison to many of the safe school policies and anti-violence programs that have been developed in response to the public perception that violence and aggression in schools has been growing (Jull 2000, 1) since the early 90's when school shootings in North America first occurred. With its focus on valuing the worth of all and the importance of healthy relationships it contrasts sharply with the Ontario Ministry of Education's Safe Schools Act (2000) which relies heavily on punitive and standardized discipline in which offenders are understood as the cause of the problem. The policy, which resulted in a sharp increase in student suspension and expulsion rates and a wide variety of anti-violence programs, did little to assure students, teachers and parents that their school environments were safer and clearly illustrates the damaging impact ineffective legislation and programs can have not only within schools but also in the broader communities where youth gang activity and violence also increased (Jull 2000, 4). In April 2007 Ontario education minister Kathleen Wynne announced that the whole concept of zero tolerance was a failed idea and the Ontario Safe Schools Act 2000 was being amended and replaced by alternatives that downplay automatic suspensions and expulsions in favour of supports such as counselling, mediation and rj (CBC News 2007, April 10). With the inception of the Ontario Ministry of Education's Bill 212 in February 2008, school boards in the province are now looking seriously at using rj principles to provide insight into how to shift from the "strict discipline policy" of the Ontario Safe School's Act 2000 to the more inclusive, relational expectations in the act that is being described as a "progressive discipline and safe schools bill" 
(Ontario Ministry of Education 2007). To assess the effect of these changes and the specific rj initiatives school boards and schools are taking up, critical theory provides significant insight.

To illustrate why critical theory is significant, there are many critical education theorists I could draw on. For the purpose of this paper, I have selected Paulo Freire and bell hooks, however, as they are not only critical theorists in their own right but also engage with critical pedagogy which "is preoccupied with social injustice and examines and promotes practices that have potential to transform oppressive institutions or social relations, largely through educational practices" (Keesing-Styles 2003, 2). This is important as rj in education seeks to transform the current rule-based, managerial cultures of schools which requires not only an analysis of oppressive power relations and inequalities therein, but also an active response.

\section{Paulo Freire}

Paulo Freire, in Pedagogy of the Oppressed (1970) articulates an understanding of humanity that resonates with and strengthens rj's conceptual framework. He identifies that people have come to accept that they are 'beings for others' reduced to the level of object by an oppressive, powerful minority. He refutes that humans are adaptable, manageable beings and instead calls for transformed social structures that allow people to become 'beings for themselves,' with an ontological vocation of being more fully human (73-75). This is beneficial as this process of humanization which, according to Freire, comes to life through pedagogy that uses dialogue to increase conscientization of limit-situations for the purpose of transformation, is mirrored in rj practice. As such the transformative nature of $r j$ with the essential components of deep respect for humanity and community becomes clear. To explain the relevance of Freire's critical pedagogy for $\mathrm{rj}$ in education, I will describe how it can be observed in a rj circle process, 
the particular strategy that is used most often to introduce educators to the potential of rj for their schools. To begin, a simple description of a circle is helpful:

Harm has occurred. The one causing the hurt admits involvement, the one hurt is willing to describe the impact of the incident and both agree to meet in a rj circle process. Each has a relative or friend present as a support and advocate. These along with several others who have been affected indirectly, attend. A facilitator is present and facilitates a dialogue where each person present is given time to share their stories by responding to key questions such as: what happened? What were you thinking/feeling at the time and now? How has this impacted you? Who else has been impacted and how? What's been the hardest thing for you? What do you need/can you offer for the harm to repaired? What do you need in order to move forward? As each shares their story the harmful episode is unravelled and a plan is put in place by all participants that most often involves each of them in the reparation of harm and the restoration of relationships.

In deciding to come to such a place of dialogue, participants confront what Freire names a limit-situation - the spot between a situation that limits one's own freedom (99). This choice to act in hopes of change is made either consciously or unconsciously. Once in circle, the limitsituation that has been imposed upon them as well as their own personal limits and brokenness become more clearly defined as participants are given the opportunity to name the event and its impact on their lives - a realization that would not have emerged alone and leaves them with a choice--to be agents of change or to accept themselves as objects unable to affect change. This concept of limit-situations expands the notion of restoration to include limit-situations that people confront both within community and within themselves leading to deeper understanding of rj as a framework rather than a strategy.

Becoming aware of the impact of limit-situations on peoples lives helps to reveal inconsistencies and gaps within a school environment as people are often reluctant to face a limit-situation preferring instead to avoid confronting the causes. It is not unusual for administrators to resist conducting full circles, hiding behind excuses of 'no time'; it is not 
unusual for teachers to resist inviting in those affected indirectly; it is not unusual for students or parents to refuse to participate in a circle choosing exclusionary measures instead. When this occurs, Freire's critical approach suggests the presence of power structures restricting the opportunity for individuals to emerge from their submerged reality and perceiving the causes of their needs (117). The nature of these power relations highlight the need from a Freirian standpoint, for creating spaces for dialogue.

Dialogue, according to Freire (1970), is the encounter between people who understand their common vocation to be that of naming the world and changing it so all can become more fully human (88). Such naming consists of 'true words' spoken to transform the world, not 'false words' spoken to diminish or destroy the world; such naming is

not the privilege of some few persons, but the right of everyone. Consequently, no one can say a true word alone - nor can she say it for another, in a prescriptive act which robs others of their words (88, emphasis in original).

This concept of dialogue is critical in terms of deepening the conceptual framework of rj. Though dialogue is understood to be at the heart of rj and is considered to be the vehicle through which all parties involved can collectively share their stories and then decide what is best for bringing about restoration, Freire's emphasis that no one can say true words for another is intended to unveil hegemonic power structures that, if left untouched, make full restoration/transformation impossible as circle participants are simply returned to the environment that allowed the harm to occur in the first place. Understood from this Freirian perspective, schools engaging with rj can more fully embrace dialogue by being aware that the institution must be considered a participant in circle processes. This is not easy to accomplish given that schools as institutions involving hierarchical structures reinforce and normalize the 
imbalance of power relations so that students and teachers defer, fearing freedom and choosing instead to maintain the status quo (Freire 1970,36). This comes about because schools are sites where speaking FOR another is a regular, dehumanizing occurrence and sites where the proliferation of words expressed do not reflect a balance of action and reflection. The level of dialogue rj is reaching for disintegrates into either verbalism or activism, neither of which can bring about the sought after transformation (87). In order for dialogue to be transformative it must bring about conscientization.

Human beings are because they are in a situation. And they will be more the more they not only critically reflect upon their existence but critically act upon it... Humankind emerge from their submersion and acquire the ability to intervene in reality as it is unveiled. ... Conscientizacao is the deepening of the attitude of awareness characteristic of all emergence (109, emphasis in original).

In a rj process conscientization potentially occurs for each participant as they listen to and share their stories becoming aware that the experience has had far greater impact than known previously. This realization can then lead to a personal and collective commitment to act. Freire's notion deepens this aspect of $\mathrm{rj}$ by highlighting that conscientization emerges from a rethinking of assumptions:

I cannot think for others or without others, nor can others think for me. Even if people's thinking is superstitious or naïve, it is only as they rethink their assumptions in action that they can change. Producing and acting upon their own ideas - not consuming those of others - must constitute that process. (108, emphasis in original)

Again this is not easy to accomplish in a school setting where students, teachers and administrators are typically expected to fit into and follow a daily regimen and not think for 
themselves. The concept of the institution itself encouraging people to produce and act upon their own ideas is not only difficult but destabilizing as this will require systemic change when the dialogue reveals how institutional structures and assumptions contributed to the harm. $\mathrm{Rj}$ in its encouragement of conscientization will not allow for predictable order to govern the daily experience of the institution which then will also require revolutionary leadership:

To simply think about the people ... without any self-giving in that thought, to fail to think with the people, is a sure way to cease being revolutionary leaders ...there is only one way for the emerging leaders to achieve authenticity: they must 'die,' in order to be reborn through and with the oppressed... leaders can flourish only in communion with the people (Freire 1970, 133, emphasis in original).

To illustrate how the three significant characteristics of Freire's anti-oppressive theory, limit-setting, conscientization and dialogue, influence rj in schools consider specifically the formal circle process described above that is encouraged as an alternative to a student being suspended or expelled. The facilitator creates a space and invites dialogue to occur amongst the student facing suspension, those seen to have been harmed by his/her actions, parents, teachers and others who have felt the impact of the action as well as the looming suspension. Already in deciding to come to such a place, participants must have acknowledged and begun to confront a limit-situation in hopes of finding change. This limit-situation becomes more clearly defined as participants are given the opportunity to name the event and its impact on their specific lives. Through telling and listening people are brought to a consciousness of the situation that had not been possible alone. When this occurs the group as a whole can brainstorm for ways in which to undo the harm that has been done and collectively decide what is best for them all as a community. 
In this example, I propose two things occur. First, the impact of the situation affects the participants as individuals. Each recognizes their own limits, their brokenness, and their humanity as well as these human qualities in the others engaged in true dialogue with them in the circle. As this is acknowledged by all, the masks often worn in public to hide our limitations are removed and collective vulnerability provides an environment where participants are willing to help and support each other as well as take responsibility for their role in the situation. This is an example of conscientization where "individuals who were submerged in reality, merely feeling their needs, emerge from reality and perceive the causes of their needs" (117).

This sets the stage for the second occurrence which Freire (1970) states is the point at which participants are motivated to participate in the resolution of the issue at hand. The participants now begin to see themselves as a collective group and they address the role of individuals as well as of the institutional structure in regards to the issue at hand. In essence community conscientization grows and together people confront the limit-situations imposed by the institutional structures that are confining them. The group may identify issues such as: inconsistencies in policy; lack of input by students, teachers and parents into the guidelines governing the school; a hierarchical governance structure that people experience as dictating a vision that prohibits an expression of who they are and what they need; few avenues for expressing concerns and ideas; or roles and responsibilities that are not carried out adequately. When these types of concerns are put forward as a group, a sense of agency has the potential of developing and together the group feels they have opportunity to confront and act to change the limits that have allowed for the harmful event to occur in the first place. In this way rj practices used in schools have the potential to open up spaces to interrogate and to reflect critically on the 
effects of oppressive power relations from within the very educational institutions in which the teachers and students are working to build more equitable and humane conditions.

This becomes a pivotal point in the effective implementation and sustainability of $\mathrm{rj}$ in schools. Though those in leadership positions initially may be willing to provide space for dialogue, the challenge to overcome will be if they are truly open to such an analysis of the institutional structure where they find their purpose. Will they see themselves as part of the community and thus willing to let school participants have this kind of agency?

This specific example of a full restorative circle and the possible recommendations for change that may arise from it reveals inconsistencies and gaps between rj theory and practice. To further illustrate, consider the following example of a school community, which in principle has adopted a restorative philosophy to guide it, but is reluctant to use full restorative circles when a situation arises that could be addressed by implementing this strategy. By enquiring into the reason for this, the oppressive intent on controlling social behaviour may be uncovered. Where is the apprehension coming from? Are the administrators fearful of what may be requested of them? Are the participants afraid of their responsibility in the event being revealed? Is the administration intent on controlling who is included and who is excluded from the circles? Do participants invited to attend decline the invitation? If a circle is convened, is dialogue interrupted and manipulated by those in authority? Are ideas generated by the group dismissed by those responsible for school structure?

Freire's analysis of power relations developed or arose out of his experiences of engaging with oppressed people; restorative practice in education began by engaging with people in conflict but has not yet seriously considered the underlying role power plays in these situations as is indicated by its marked absence in the research available to date. Until this is done, $\mathrm{rj}$ in 
education will run the risk of being co-opted (Fetherston 2000; Morris 1998) as schools, especially elementary and secondary schools, continue to identify and deal with issues as if the problems in the school begin with those causing harm and resolving conflicts requires that only the disputants perceptions of each other and the situation be changed. When this occurs, the transformational potential of $\mathrm{rj}$ and the hope for a paradigm shift regarding the concepts of justice and conflict will never take hold. By engaging with these issues of power and social relations that come from specific issues and instances of conflict there is hope as a deeper reflection on how structural factors support or impede effective implementation of rj in schools becomes possible.

I have used Freire's (1970) insights to examine formal rj circles held in response to serious issues of conflict and harm. With young children and youth a myriad of lesser issues arise constantly. Are questions of institutional structure and power relations to be addressed in every instance? Are young children and youth interested in dealing with their minor relationship incidents with such seriousness? Such expectations are unrealistic of course, but what Freire uncovers in his concept of humanization is how shifting from a rule-based to a relationship-based paradigm affects not just how issues of behaviour are considered but more importantly how it affects our view of each other, our way of being in the world, and our way of interacting with others. In this way as educators in our engagement with very young children, youth, or adults, in situations of minor hurt or serious, our practice changes as our intent is to support everyone's well-being in their vocation of becoming 'beings for themselves'-more fully human (74-75). To further elaborate on this integration of humanization in the minuscule details and the large, I turn to bell hooks who models how deeper reflection turns into action as it reaches into the daily activity of the school. 


\section{bell hooks}

bell hooks' $(1994,2003)$ work draws on Freire's concept of humanization in her commitment to intervene in Western sexist and racist cultures of domination. In so doing, she explicates further that the focus cannot just be on the individual, the conflict, or healing, without taking into consideration broader socio-political and cultural forces at play or the broader institutional context of an individual's life or circumstances. Where Freire (1970) provides a pedagogy for becoming aware, naming and then acting to undo oppression, hooks (1994) takes this concept of praxis and examines if the action taken to undo the oppression is in fact any different than the dominant power it is replacing (6). It is from this critical vantage point that hooks models for us and challenges us to see that to undo oppression we need to look inward, we need to change who we are and how we educate. It must be integrated into the very fabric of education. In so doing, hooks provides for $\mathrm{rj}$ in education a model for interrogating the theory-practice divide and the concept of community as a space for healing and justice.

Wachtel (1999) in defining restorative practices as "an emerging field of study that enables people to restore and build community in an increasingly disconnected world" echoes hooks (2003) when she says 'education as the practice of freedom, enables us to confront feelings of loss and restore our sense of connection" (xv). To approach education in this manner hooks identifies as crucial, the union of theory and praxis (x) for the purpose of re-contextualizing individuals and rebuilding community. hooks in her commitment to reducing racism and sexism in education models how interrogating bias uncovers authoritarian institutional educational infrastructures that have bred a culture of fear, shame and domination $(43,94,130)$. It is this encouragement to question that deepens the practice and theory of $\mathrm{rj}$. What happened to 
influence schools to adopt rj principles to guide their interactions? Who benefits most from rj practices? Who bears the burden of $r j$ in the school? Who and what are being restored in the rj practices employed? Are rules or relationships in the forefront of the rationale for a rj practice? Is space provided for healing? Are educators and policy makers conscious of and working against the culture of fear, shame and domination? Eventually out of all this questioning, a summary question emerges that is instrumental in further closing the gap between theory and practice: in what is being named as $r j$, what message is being sent? Is it a message of adults wishing to reinforce control or one that encourages relationship and respect? In whatever capacity one serves (teacher, parent, researcher, student, administrator), if committed to rj, do actions convey an intent to live restoratively? In asking this question at both institutional and personal levels inconsistencies and gaps are discovered that then point to hegemonic power structures.

hooks (1994) models this interrogation and provides another powerful insight for the sustainability of rj in identifying how curricula and pedagogy are sites of disconnection when they carry biases that "reinscribe systems of domination" (10). Education that seeks to change social structure, according to hooks, must be reflected in curricula and pedagogy. Engaged pedagogy integrates theory and praxis. It emphasizes well-being, connects life to learning, values student expression, empowers students and teachers, and transforms the curriculum so that it does not reflect biases or reinforce systems of domination (13-22). Engaged pedagogy ensures that pedagogy and curriculum do not undermine the dignity and worth of learners and learning. This leads to a transformed classroom which in turn will lead to transformed lives that extend beyond the classroom. If rj practices in education which are intent on shifting paradigms and changing social structures are to be effective, then pedagogy and curricula will impact and be impacted by its presence. hooks thus provides rationale for examining pedagogy and curricula in 
schools committed to rj, as doing so will reveal a school's present commitment to its use as well as open up avenues for sustainability.

Finally, in returning to hooks central concern of developing community with justice as its core foundation, rj which seeks to re-establish connected communities can be deepened. How can rj avoid the influence of dominator culture and move towards truly connecting people in a disconnected world? hooks perspective on the essence of community helps in this regard as she connects community, teaching, justice, and healing. For hooks (2004) education as the practice of freedom requires that teaching community with justice as the core foundation be central (xvi). Justice, for hooks (2000) is intertwined with love and is not about reducing inequality but relieving domination that exploits and oppresses (xiii). This combined with Peck's definition of community, which she embraces, provides spaces for healing that promotes wholeness:

Community is the coming together of a group of individuals who have learned how to communicate honestly with each other; whose relationships go deeper than their masks of composure, and who have developed some significant commitment to 'rejoice together, mourn together,' and 'to delight in each other' and make the conditions of others' our own (Peck in hooks 2003, 196, emphasis added).

In this space reparation, healing and restoration occur because pain and brokenness is named, given over to a trusted community, and then transformed over time.

It is not easy to name our pain, to make it a location for theorizing ... I am grateful to many women and men who dare to create theory from the location of pain and struggle, who courageously expose wounds to give us their experience to teach and guide, a means to chart new theoretical journeys (hooks 1994, 74). 
In naming the role of pain and brokenness in generating theory, hooks identifies that community is created when together people acknowledge their woundedness and then look through it to the source of the hurt. Participants see their place in a larger context and recognize how their personal actions are intertwined with broader social structures. This is important. Healing and wounding are not and cannot be conceptualized at the level of the individual without connecting the individual's pain and suffering to the impact and/or effect of broader institutional, political and social forces. When such a community is established, the deepest ruptures can be tended and prepared for healing. Such communities can be created in schools when people are committed to education as the practice of freedom (Freire 1970, 93; hooks 1994, 207) where freedom is defined as the "capacity ... to look at things as if they could be otherwise" (Greene 1988, 3).

As it is my premise that $\mathrm{rj}$ in education encourages just such a communal healing space, hooks' insights first of all provide a guide for examining if current rj practice in schools contribute to communities with justice as their core foundation, then extends this to recognizing how engaged pedagogy is the vehicle through which this community is actualized.

To further the argument that critical theory is significant for the effective implementation of rj in education, Freire's and hooks' insights are employed in the following examination of two key rj frameworks.

\section{Using critical theory to examine two key restorative justice frameworks}

Reintegrative shaming theory and the social discipline window are two theoretical frameworks drawn on extensively in the implementation of $r j$ in education and are often woven together in the literature and training provided for educators. The following description of these 
frameworks illustrates their contribution to the field thus far, while a critical analysis of them opens the way for a deeper knowledge base that can inform more effective practice.

John Braithwaite (1989, 2001) Australian criminologist and social scientist proposed and tested his psycho-social theory of reintegrative shaming as the basis for why rj is effective for reducing crime. Using Donald Nathanson's (1996) affect theory and in particular his empirical research that indicates people's four ineffective responses to shame, Braithwaite \& Braithwaite $(2001,4)$ introduce how the role of shame and shaming are central to the project of rj. By distinguishing between stigmatized shaming--treating the wrongdoer disrespectfully as a bad person--and reintegrative shaming--treating the wrongdoer respectfully and empathically as a good person who has done a bad act and making special effort to show the wrongdoer how valued they are after the wrongful act has been confronted--Braithwaite presents a rationale for how treatment of offenders and victims can influence long term behaviour. Convinced that shame is always present and one of the tools used in the advancement of social movements (5), Braithwaite and his colleagues have invested a significant amount of time researching how people have dealt with shame in the context of crime as well as child development. This work is important in terms of understanding what occurs in formal rj conferences. Here is a space in which the people affected by the event--the victim, offender, and their communities-- have an opportunity to share their stories. Braithwaite argues that this provides a safe space in which the offender when hearing the impact of his/her action, has an opportunity to experience shame, express remorse and then be accepted and supported by the community as together the group decides on how to deal with the harm done. This would also be considered a place in which the shame the offender and victim have felt since the event, can be managed in a positive manner. Research indicates that both the people who offend and the victims who feel shamed by the harm 
done to them, struggle to know how to deal with their shame if not given opportunity to do so (Ahmed 2001; Nathanson 1994). Stigmatized or ignored shame can result in the offender reoffending, or offending with greater aggression. On the part of the victim, it can result in harming self or acting out against others. In fact, most offenders are people who have been victims themselves (Ahmed 2001; Nathanson, 1996). Braithwaite's perspective is important to consider for rj in education since researchers and practitioners have relied on Braithwaite \& Braithwaite's (2001) reintegrative shaming theory to the point that shame is currently considered to be one of three central concepts in rj literature (Morrison \& Ahmed 2006, 213)

Using Freire and hooks, this notion of shaming and reintegrative shaming not only appears limited but also emerges as an instrument for objectification. Though the intent is to reestablish the role of community in a person's life, the community and the circle process when used in this manner takes on an omniscient character that zeros in on the harmful incident and sets about to control the 'offender's' behaviour and the 'victim's' healing. Though each of these parties has a voice in the circle meeting and there is a possibility that their voice will impact the consciences of the rest of the group, the theory, simply by labelling the participants as 'offender' and 'victim', continues to decontextualize the one who has caused harm and the incident itself from the context in which it occurred. Through interrogating bias and promoting engaged pedagogy, hooks also provides a perspective on the reality and impact of shame. Though Braithwaite distinguishes clearly between reintegrative and stigmatized shaming, he does not recognize every circle participant's experience of shame in the incident which hooks' (2003) does. She pushes past shame as an isolating, individual experience when she draws on the work of Kaufman and Raphael who remind that "all human beings stand equal in the sudden exposure wrought by shame... shame shadows each of us, and everyone encounters the alienating effect in 
some form, in some time" (102). When this is understood, community becomes a place of collective vulnerability where people know what it is to falter and fail (Moore, D. 2004, 78). It is this collective willingness to be vulnerable, this recognition of brokenness that becomes central in theorizing rj, not the shame itself. Though rj draws on this concept of community as a group of people supporting the harmed and the one causing the harm, by theorizing about shame only in terms of the one who has caused the harm, a hegemonic structure emerges that uses shame to control. The intent of those committed to r $j$ to find healing within community is noble, however by using shame to theorize rj the focus becomes one of restoring community to what it was--a place characterized by boundaries and expectations--rather than transforming it to what it could be -a place characterized by possibility, relationship, hope, and justice. Thus using critical theory problemetizes the very term "restorative" and provides support for the significant work of justice activist Ruth Morris (1998) who advocates for a deeper conceptual understanding of restorative justice that includes the use of the term "transformative justice" instead.

Braithwaite's (1989) theoretical work is drawn upon consistently in the various settings that engage with rj including the research done in education. Of note in terms of rj theories in this field is Ted Wachtel's (1999) social-discipline window. This early psycho-social theory focuses on the individual in community where young people are seen to be relational, emotive beings whose inherent sense of worth is restored, maintained or nurtured when affirmed by the trust and support of adults who are able to provide an environment of high control of wrong doing and high support of the individuals. Without this a person's sense of well-being is violated; with it they are restored.

In designing the social discipline model, Wachtel (1999) draws on Braithwaite's (1989) reintegrative shaming concept to expand on the limited punitive/permissive model of punishment 
used to control wrongdoing that is evident in many schools, homes, and communities today. Instead of seeing only two response options to misbehaviour, to punish or not to punish, they suggest a broader perspective that will encompass people's inherent need for relationship in supporting their sense of worth as a restorative option. The permissive, neglectful, and punitive windows all are inadequate as they rely on stigmatized shaming and send messages that undermine a person's sense of worth and well-being and exclude them from relationships and community (see Fig.1).

[Insert Figure 1]

The restorative quadrant, where the term with is essential and illustrates Wachtel's understanding that humans have a need to be in relationship, sends a message of hope for healing and provides for opportunities in which students can express their emotions, deal with their feelings, and find support for their growth in understanding relationships. Here teachers involve students directly in the process of discipline and when necessary include those harmed--family, peers and community. How can this be done? By providing an environment of high control of wrongdoing (not of people) and high support of the worth of people (Wachtel 1999, 2) that says in essence, 'I do not like what you are doing, but I like who you are so let me walk with you as you solve this problem' (based on reintegrative shaming). This understanding, they explain, is worked out through a continuum of restorative practices.

[Insert Figure 2]

These practices, which rely on adults using several key rj questions to confront students is thought to encourage participants to look at the impact of their actions on others and find ways of 
repairing harm done. They are used throughout the school day as incidents occur. Though teachers most often implement the practice, as students become more familiar with them they too begin to use them with each other as needed. Using hooks (1994) notion of engaged pedagogy, this continuum is exposed for its limited engagement with rj as a reaction to behaviour again, not a proactive means for building relationships and community that is integrated into all aspects of education. As a result the rule-based managerial school structure that rj seeks to replace, is ultimately reinforced.

Braithwaites' (1989) reintegrative shaming theory and Wachtel's (1999) social discipline window theory are helpful on many levels. First, they have brought facets of rj beyond the judicial context to social environments such as classrooms, schools, families, and communities. In so doing they have acted upon the premise that rj requires a paradigm shift that will impact all of life. Second, they uncover aspects of how individuals respond to harmful behaviour they engage in and the narratives given by those who have been hurt. Third, they provide a broader context for understanding effective discipline and communication between adults and youth. Finally, each of the theories have moved the field forward and have become springboards for delving into a deeper understanding of $r j$ as a way of life rooted in respect for the other and the need for healthy relationships.

By identifying the limitations as well as the strengths of Braithwaite's and Wachtel's theories in the context of education the elaboration of a more sophisticated framework capable of addressing the socio-political context in which individuals are located becomes possible. In this regard I argue that what is needed in the field, is a conceptual framework that draws attention to the significance of the institutional and structural forces at play in shaping an individual's beliefs and actions. To do this I begin by reflecting again on the insights of Morris (1998) who points 
out that "accepting the myth that problems in the world begin with the offender, by ignoring structural injustice, by attempting to restore the past, $\mathrm{rj}$ is vulnerable for co-optation" (summarized from Morris in S. Moore 2003, 34-35).

Both the reintegrative shaming theory and the social discipline window acknowledge the structural changes in institutions that will occur if individual needs are attended to. Both celebrate the healthier culture that results when communication is more respectful and honours the worth of all. However, both theories focus on the victim and offender and what occurs within their individual psyches while failing to take account of the institutional and structural forces at play in shaping the beliefs and actions of individuals. When examining rj circles within the context of these theories, though the intent is to place all affected and their relationships at the centre of the circle, and the hope is that the educational institution will change, the theories depend on the impact of the circle on the one causing the harm and the myth that Morris speaks of is perpetuated. David Moore (2004) highlights the limitation of reintegrative shaming and the social discipline window when he identifies the profound sense of change all participants in a circle speak of experiencing and that this change is not dependent on the offender feeling remorse, but rather on the telling of each participant's story and the space provided by the facilitator for reflection. This understanding appears to be grounded in the premise that as people confront their own imperfection, a collective vulnerability is uncovered which ensures a shift in the emotional dynamics of the group (87). Moore's contribution opens the way for a more productive approach than that provided by Braithwaite and Wachtel as it shifts the focus away from the individual to the broader context of social relationships. Within this context, where the group confronts broken relationships, there is greater potential for a more analytic approach that is capable of identifying the limits of the existing structures such as power imbalances or 
inadequate support. But even in highlighting relationship Moore fails to move the focus beyond the individuals involved to a consideration of their beliefs and actions within a broader sociopolitical and institutional context. Failure to address structural and institutional influences risks reducing an understanding of rj to a decontextualized skill-building exercise committed to producing empathic social relations. This ignores the necessity of requiring individuals to reflect deeply on how their actions and beliefs are enmeshed in broader systemic social and institutional contexts in which power relations are negotiated. White (in A. Morrison 2001) in speaking of his experience with young offenders, identifies the necessity of this when he states that no matter how remorseful or shamed an offender might be, and no matter how welcoming the offender's communities of care might be in his or her return to the fold, if the structural causes of that offending remain untouched then reoffending seems likely (11).

A further limitation of these theories for the school setting includes the potential misuse of power in the relationship between adult and youth—teacher and student. Wachtel's (1999) social discipline window is designed using the principle that a student's inherent sense of worth is restored, maintained or nurtured when affirmed by the trust and support of adults who are able to provide an environment of high control of wrong doing and high support of the individuals (IIRP 2003). This premise though noble in its articulation of the responsibility adults have in nurturing youth, opens the door to understanding rj as primarily a means for managing student behaviour in a school environment. Though perhaps not punitive in nature, by identifying the window as functioning on the basis of the relationship between teacher/student or adult/child instead of a means by which to understand the exercise and effects of specific sorts of power relations, the purpose of using rj in education can be questioned and misconstrued and adultist agendas can set 
in. The problem once again is the focus on the decontexualized individual and on human interaction and relations as divorced from a socio-political and cultural context for understanding the nature of power, conflict and violence. This separation Giroux (1981) states in his discussion of the contribution Freire makes to North American education, is at the source of understanding problems that plague schools.

Only by viewing schooling as a semi-successful agency of legitimation within the context of larger socio-economic forces can one begin to understand the source of the problems and contradictions that in large part plague the schools. The prevailing forms of knowledge, values, social relationships and forms of evaluation that are used in schools do not exist in precious isolation from the larger society. They are linked, for the most part, either directly or indirectly to the prevailing cultural hegemony and dominant economic arrangements (130).

Though Braithwaite and Wachtel are aware of the importance of the relational aspect of $\mathrm{rj}$, their focus is limited to the relationships between individual people. Without locating these individuals and the nature of their interactions within their broader social and institutional contexts their communal, social needs and responsibility are lessened and the potential misuse of power seems close at hand. By employing such critical reflection a deeper understanding about the motivations and the forces at play that drive harmful behaviour and conflict in school contexts emerges. The complexity of hierarchical power relations are uncovered allowing the transformative potential of $\mathrm{rj}$ is to be realized. Herein lies the significant contribution of critical theory.

\section{Implications for implementation and sustainability}


As critical theory meets restorative practices in education implications for successful implementation and sustainability are more readily identified than when guided by the theories of Braithwaite and Wachtel.

When critical theory informs and strengthens the rj framework, implementation and development go far beyond a focus on student behaviour. It does this in a variety of ways. First, it challenges its proponents explicitly to define rj and indicate how it informs and furthers our understanding of creating educational communities committed to honouring all people. When this is done, rj gradually penetrates and changes the institutional structure so that day to day interactions of minor and major significance are considered in a relational light. Second, it requires that questions be raised about the pedagogical significance of rj practices within the context of schooling. Critical theory opens the way for restorative practices to be understood as crossing disciplines rather than being a separate discipline that falls under and is limited by the banner of safe schools, peace building, citizenship education, or classroom management. In this way rj is understood in broad pedagogical terms with implications for all facets and fields of education including how adults relate to each other and students, curriculum choices, evaluation and assessment, committee composition, the physical environment of the school and classrooms, and much more. Thus critical theory challenges its proponents to recognize engaged pedagogy as critical if promotion and acceptance of rj practices are to occur. Finally, critical theory highlights that rj regard as essential the place of caring relationships in education where the purpose of education is "not to dominate, or prepare [students] to be dominators, but rather to create the conditions for freedom. ... allowing students to embrace a world of knowing that is always subject to change and challenge. (hooks 2003, 92). As schools worldwide and in Ontario specifically continue to engage with restorative practices, by drawing on critical theory, a clearer 
understanding of what restorative practices and $\mathrm{rj}$ are in the context of education emerges and more effective means of implementation can be developed.

This is much more in keeping with understanding $\mathrm{rj}$ as a philosophy that requires a paradigm shift. Though this does not happen over night, when understood as such, rj has the potential for penetrating the very fabric of the institution and people come to know they are respected, have a voice, and have opportunity to be agents of change. Institutional structures and those in charge are no longer intent on retaining power and dominating but instead see institutions and leadership roles as organic with the purpose of supporting and encouraging humanization. Change becomes less and less of a threat.

\section{Yes, but ...}

The premise that critical theory and the specific insights that Freire and hooks contribute to a deeper understanding of $\mathrm{rj}$ for education are significant. But just as critical theory uncovers the gaps in the early and current practices of rj in education, so too, it continues to be important to reflect critically on these contributions that highlight the institutional, hegemonic structures currently impeding rj's successful implementation.

To begin, it is important to acknowledge that Freire and hooks both employed critical theory in developing critical pedagogies that addressed issues of power and institutional structures in the lives of adults. As suggested earlier, one could argue that their insights do not apply to elementary and secondary schools where children and young people require a nurturing supportive environment different than adults. In making the case for the significance of critical theory in the field of rj in education however, this article highlights the fact that it is adult educators, researchers and practitioners who are implementing rj into school systems and it is their engagement with rj that will either reinforce or transform adultist, hierarchical intentions 
that currently support rule-based managerial structures of schooling. Not only this, but the insights of Freire and hooks also call attention to the fact that concepts of humanization, community, and conflict are universal and of as much importance in the lives of young people as adults. It is the responsibility of adults to create nurturing environments for youth that encourage and guide them to interact in ways that do not cause harm or repairs harm when it occurs. This is modelled for youth both in the relationships built between them and the adults around them, as well as in the expectations set for them in creating and maintaining relationships with peers. It is also modelled and presented to youth in how and what they are taught as indicated by recognizing the significance of engaged pedagogy.

Next, the criticisms of critical pedagogy offered up by Ellsworth (1989) are important to highlight here in light of her discussion regarding student voice, safe spaces and dialogue. With rj's emphasis on these same qualities, in its effort to build relationship-based cultures it is important to realize that "acting as if our classroom were a safe space in which democratic dialogue was possible and happening did not make it so" (315). Commitment, she discovered with her students, was not enough to make a setting a safe space for speaking out. High levels of trust and personal commitment to each other were required; dialogue needed to occur not only as individuals but as a coalition of people dedicated to honouring each other's humanity. Though these insights arise out of Ellsworth's critique of critical pedagogy, they further support the conclusions I draw having used the work of hooks and Freire regarding the need to emphasize the importance of building relationship and community through engaged pedagogy. In this light, the contribution critical theory makes is not dismissed but deepened and Ellsworth's insights stand as a caution, as a gateway into a further analysis of current rj practices. In this regard, this 
paper stands only as the beginning of the contribution critical theory can make to the field of rj in education.

\section{Conclusion}

Dominant power structures are a reality in western democratic societies. Ringma (2000) indicates that people have difficulty recognizing this as such because we simply take for granted so much of our social world and believe that the very institutional realities surrounding us sustain our lives. In order to reveal how people have been objectified and diminished he states that 'we need to become critical of the very systems that give order to our society' (13). $\mathrm{Rj}$ when informed by critical theory opens up opportunities for this to occur in educational institutions and will provide new hope for the restoration of what both Wachtel and hooks identify as central to learning - connection and community.

Wachtel (1999) in describing what brought him to integrating rj with education identifies that "the increasingly difficult and violent behavior among school students and related punitive school climate are both products of the alienation and loss of community that plagues modern society in general" (1). hooks (2003) states:

One of the dangers we face in our educational systems is the loss of a feeling of community, not just the loss of closeness among those with whom we work and with our students, but also the loss of feeling of connection and closeness with the world beyond the academy ... progressive education, education as the practice of freedom, enables us to confront feelings of loss and restore our sense of connection. It teaches us how to create community (xv).

At the heart of rj as a new paradigm is the restoration of our sense of connection with one another. With the entrance of rj into educational institutions, critical theory is a tool that expands the notion of relationship so that includes peoples interactions not just with others but with their 
environments. It has the ability to unveil and address structures that promote alienation and brokenness. With this awareness, rj spaces can be created in which relationship is emphasized rather than decontextualized individual behaviour and healing can occur for individuals of all ages and communities of all sizes. It is in this sense that rj practices have the capacity to embody what cultural critic and novelist Raymond Williams (1980) describes as "making hope practical, rather than despair convincing" in building communities that are committed to effectively working against the culture and politics of violence in schools (42).

\section{References}

Ahmed, E. (2001). Shame management: Regulating bullying. In Shame management through reintegration. Cambridge: Cambridge University Press.

Amstutz, L., \& Mullet, J. (2005). The Little Book Of Restorative Discipline For Schools. Pennsylvania Good Books.

Aoki, T. T. (1989). Toward curriculum inquiry in a new key (Occasional paper). Edmonton: University of Alberta.

Braithwaite, J. (1989). Crime, Shame and Reintegration: Cambridge University Press.

Braithwaite, J. (2006). Doing Justice Intelligently In Civil Society. Journal of Social Issues, 62(2), 393-409.

Braithwaite, J., \& Braithwaite, V. (2001). Shame, Shame Management And Regulation. In E. Ahmed, N. Harris, J. Braithwaite \& V. Braithwaite (Eds.), Shame management through reintegration (3-72). Cambridge: Cambridge University Press.

Braithwaite, J. (1999). Restorative justice: Assessing optimistic and pessimistic accounts. Crime and Justice, 25.

Breton, D., \& Lehman, S. (2001). The Mystic Heart of Justice. West Chester, PA: Chrysalis Books.

CBC News (2007). Ontario Schools To Ease Zero-Tolerance Rules. 
Dewey, J. (1916). How we think. Boston: Heath.

Drewery, W., \& Winslade, J. (2003). Developing restorative practices in schools: Flavour of the month or saviour of the system. Paper presented at the AARE/NZARE, Aukland.

Ellsworth, E. (1994). Why doesn't this feel empowering? Working through the repressive myths of critical pedagogy. The education feminism reader, 300-327.

Fetherston, A. B. (2000). From conflict resolution to transformative peacebuilding: reflections from Croatia. Center for Conflict Resolution Working Papers Retrieved January, 2009, www.bradford.ac.uk/acad/confres/papers/pdfs/CCR13.pdf.

Freire, P. (2005, 1970). Pedagogy Of The Oppressed (30th ed.). New York Continuum.

Greene, M. (1988). The Dialectic Of Freedom. New York: Teachers College Press.

Giroux, H. (1981). Ideology, Culture And The Process Of Schooling. Philadelphia: Temple University Press.

Hadley, M. (Ed.). (2001). The Spiritual Roots Of Restorative Justice. Albany, New York State University of New York Press.

hooks, b. (1994). Teaching To Transgress : Education As The Practice Of Freedom. New York: Routledge.

hooks, b. (2003). Teaching Community: A Pedagogy Of Hope: Routledge.

hooks, b. (2004). Feminism: A Movement To End Sexist Oppression. In K. Foss, S. Foss \& C. Griffin (Eds.), Readings In Feminist Rhetorical Theory (47-56). London: Sage.

Hopkins, B. (2004). Just schools: a whole school approach to restorative justice. London: Jessica Kingsley Publishers.

IIRP (Producer) (2003). Beyond Zero Tolerance: Restorative Practices In Schools (videorecording). Pennsylvania: Institute for Restorative Practices.

IIRP. (2009). Findings from schools implementing restorative practices. Bethlehem, PA: IIRP Graduate School.

Jull, S. (2000). Youth violence, schools, and the management question: a discussion of zero tolerance and equity in public schooling. Canadian Journal of Educational Administration and Policy, 17.

Keesing-Styles, L. (2003). The relationship between critical pedagogy and assessment in teacher education. Radical Pedagogy, 5(1), 1-6. 
Kincheloe, J. L., \& McLaren, P. (2005). Rethinking Critical Theory And Qualitative Research. In N. Denezin \& Y. Lincoln (Eds.), The SAGE Handbook Of Qualitative Research (303342). Thousand Oaks: SAGE.

Mirskey, L., \& Wachtel, T. (Eds.). (2008). Safer saner schools: Restorative Practices in Education. Bethlehem, PA: IIRP.

Moore, D. B. (2004). Managing Social Conflict--The Evolution Of A Practical Theory. Journal of Sociology \& Social Welfare, 31(1), 71(21).

Moore, S. (2003). Towards An Integral Transformation: Through The Looking Glass Of Restorative Justice (unpublished thesis). University of Victoria, Victoria, B.C.

Morris, R. (1998). Why transformative justice? Paper presented at the ICCPPC World Congress, Mexico City.

Morrison, A. (2001). Revisiting Reintegrative Shaming. Criminology Aotearoa/New Zealand(16), 10-12.

Morrison, B. (2005). Building Safe And Healthy School Communities: Restorative Justice And Responsive Regulation. Paper presented at the International Institute for Restorative Practices 6th International Conference. Retrieved September 2005, from http://www.safersanerschools.org/library/au05_morrison.html.

Morrison, B., \& Ahmed, E. (2006). Restorative Justice And Civil Society: Emerging Practice, Theory, And Evidence [Electronic Version]. Journal of Social Issues, 62, 209-215. Retrieved October 2006.

Morrison, B. (2007). Restoring safe school communities. Sydney: Federation Press.

Nathanson, D. (1992). Shame and Pride: Affect, Sex, and the Birth of the Self. New York: Norton.

Nathanson, D. (1996). Knowing Feeling: Affect, Script, And Psychotherapy. New York: W.W. Norton \& Company, Inc.

Ontario Safe Schools Act 2000: Education Act Bill 81, (2000).

Ontario Ministry of Education (December 2007). Bill 212: Progressive Discipline And School Safety - Information Session. London, Ontario.

Porter, A. (2007). Restorative Practices In Schools: Research Reveals Power Of Restorative Approach, Part 1\& 2 [Electronic Version]. Restorative Practices E-Forum, 2. Retrieved May 14, 2007 from http://www.safersanerschools.org/library/schoolresearch1.html. 
Pranis, K. (2005). The Little Book Of Circle Process: A New/Old Approach To Peacemaking. Pennsylvania: Good Books.

Pranis, K., Stuart, B., Wedge, M. . (2003). Peacemaking Circles: From Crime To Community. Minnesota: Living Justice Press.

Rawls, J. (2001). Justice as fairness: a restatement. Cambridge, Massachussetts: The Belknap Press of Harvard University Press.

Ringma, C. (2000). Resist The Powers With Jacques Ellul. Colorado Springs: Pinon Press.

Sherman, L., \& Strang, H. (2007). Restorative justice: The evidence. London: The Smith Institute.

Thorsborne, M., \& Vinegrad, D. (2002). Restorative practices in schools: Rethinking behaviour management. Queensland: Inyahead Press.

Wachtel, T. (1999). Safersanerschools: Restoring Community In A Disconnected World [Electronic Version]. Retrieved May 2001 from www.safersanerschools.org.

Wachtel, T. (1997). Real Justice. Pennsylvania: Piper's Press.

Williams, R. (1980). The Politics Of Nuclear Disarmament. New Left Review, 1(124), 25-42.

Wolterstorff, N. (2006). Teaching Justly For Justice. The Journal of Education \& Christian Belief, 10:2, 23-37.

Wonshe. (2004). How Does The "Who, What, Where And How" Affect The Practice Of Restorative Justice? In H. Zehr \& B. Toews (Eds.), Critical Issues In Restorative Justice (265-276). Monsey: Criminal Justice Press.

Zehr, H. (2002). The Little Book Of Restorative Justice. Intercourse, PA: Good Books.

Zehr, H. (2005). Changing Lenses: A New Focus For Crime And Justice. Waterloo: Herald Press.

Zehr, H. (2006, March). Restorative Justice. Lecture. Redeemer University College. 
Table 1: Two approaches to wrong doing

\begin{tabular}{|l|l|}
\hline \multicolumn{2}{|c|}{ DIFFERENT VIEWS } \\
\hline \multicolumn{1}{|c|}{ Ontario Safe Schools Act 2000 } & \multicolumn{1}{c|}{ Restorative Justice } \\
\hline $\begin{array}{l}\text { Wrong doing is a violation of Ontario } \\
\text { Ministry of Education and school rules. }\end{array}$ & $\begin{array}{l}\text { Wrong doing is a violation of people and } \\
\text { relationships }\end{array}$ \\
\hline Violations create guilt & Violations create obligations \\
\hline $\begin{array}{l}\text { Justice requires the principal/teacher/board } \\
\text { to determine guilt and impose punishment }\end{array}$ & $\begin{array}{l}\text { Justice involves the harmed, those causing } \\
\text { harm, and community members in an effort } \\
\text { to put things right }\end{array}$ \\
\hline $\begin{array}{l}\text { Central focus: offender gets what they } \\
\text { deserve }\end{array}$ & $\begin{array}{l}\text { Central focus: needs of the harmed as well } \\
\text { as those causing harm and the community's } \\
\text { responsibility for repairing harm. }\end{array}$ \\
\hline \multicolumn{2}{|c|}{ DIFFERENT QUESTIONS } \\
\hline What rules have been broken? & Who has been hurt? \\
\hline Who did it? & What are their needs? \\
\hline What do they deserve? & Whose obligations are they? \\
\hline \multicolumn{2}{|c|}{ What are the causes? } \\
\hline \multicolumn{2}{|c|}{ Who has a 'stake" in this? } \\
\hline
\end{tabular}


Fig. 1: Adapted from: Social Discipline Window (Wachtel, 1999)

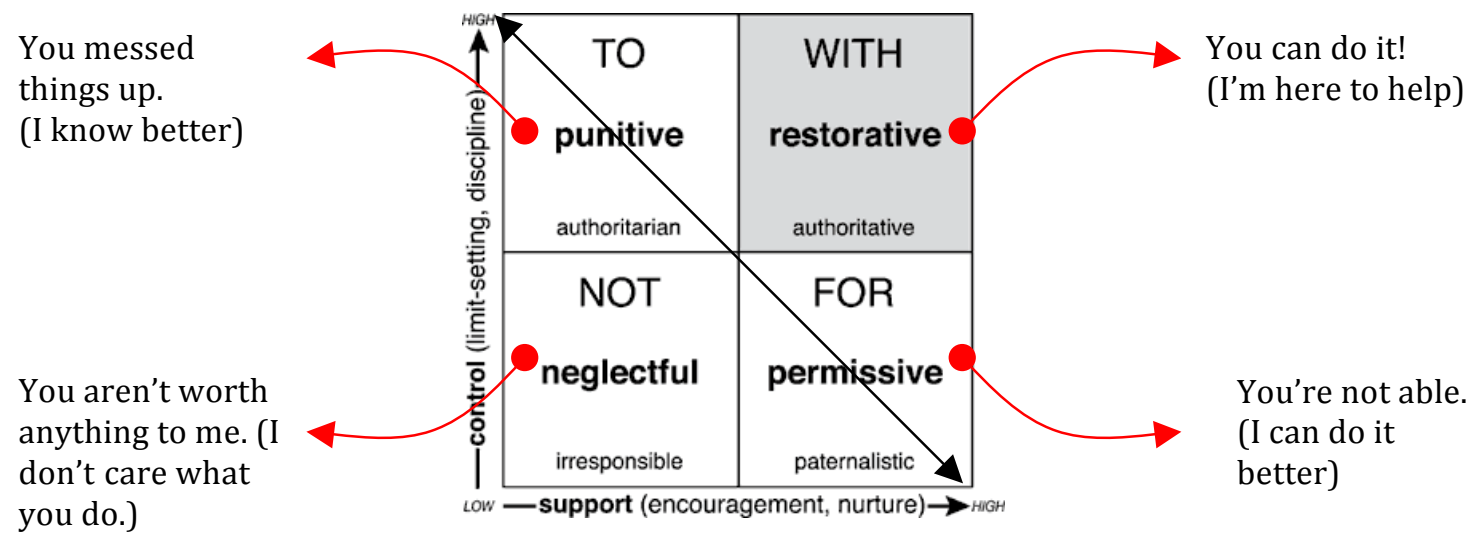


Figure 2: Restorative Practices Continuum (Wachtel, 1999)

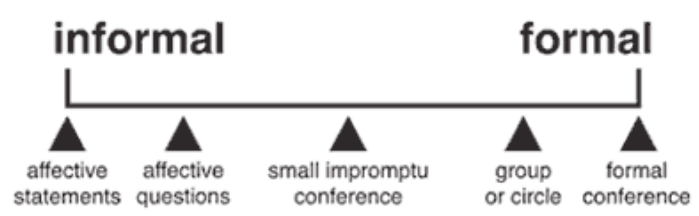


